\title{
Mengukur Penyebaran Data pada Data Tunggal Tinggi Siswa dan Data Kelompok pada Nilai Mata Pelajaran Statistika
}

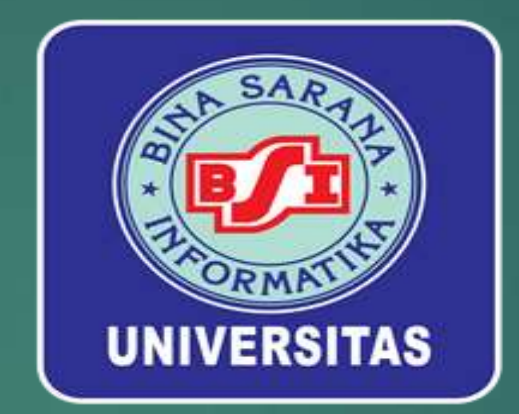

Disusun Oleh :

Diki Arif Taufiqurrohman (12183480)

Nur Syafitri (12192230)

Muhammad Rafly Alif Rachman (12193039)

Nurul Achmad Ichsan Fitrah (12191356) 


\section{UKURAN PENYEBARAN DATA}

Pengertian ukuran penyebaran data

Dispersion $=$ Maesures of Variability) adalah berbagai macam ukuran statistic yang dapat digunakan untuk Ukuran Penyebaran data

(Maesures of mengetahui luas penyebaran data

( Vasiasi data $=$ Homogenitas Data $=$ Stabilitas Data) . Adapun ukuran penyebaran data yang biasa. dihitung adalah range (rentang), standar deviasi (simpangan baku), kurtosis (keruncingan), skewness (kemiringan). 


\section{MACAM MACAM UKURAN PENYEBARAN DATA}

- Simpangan rata - rata

- Standar Deviasi

$\checkmark$ Jangkauan Kuartil

$\checkmark$ Jangkauan Persentil 
Simpangan rata-rata (deviasi mean) adalah rata-rata jarak antara nilai-nilai data menuju rata-ratanya. Simpangan rata-rata termasuk ke dalam ukuran penyebaran data seperti halnya varian dan standar deviasi. Kegunaannya adalah untuk mengetahui seberapa jauh nilai data menyimpang dari rata-ratanya.

RUMUS :

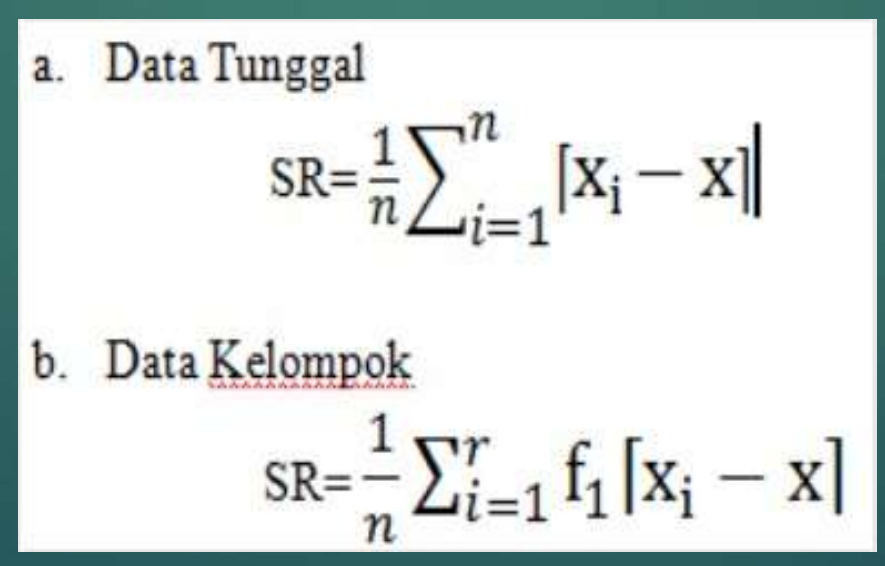




\section{STANDAR DEVIASI}

Standar deviasi disebut juga simpangan baku. Seperti halnya varians, standar deviasi juga merupakan suatu ukuran dispersi atau variasi. Standar deviasi merupakan ukuran dispersi yang paling banyak dipakai. Hal ini mungkin karena standar deviasi mempunyai satuan ukuran yang sama dengan satuan ukuran data asalnya.

RUMUS :

$\checkmark$ DATA TUNGGAL

$\checkmark$ DATA KELOMPOK

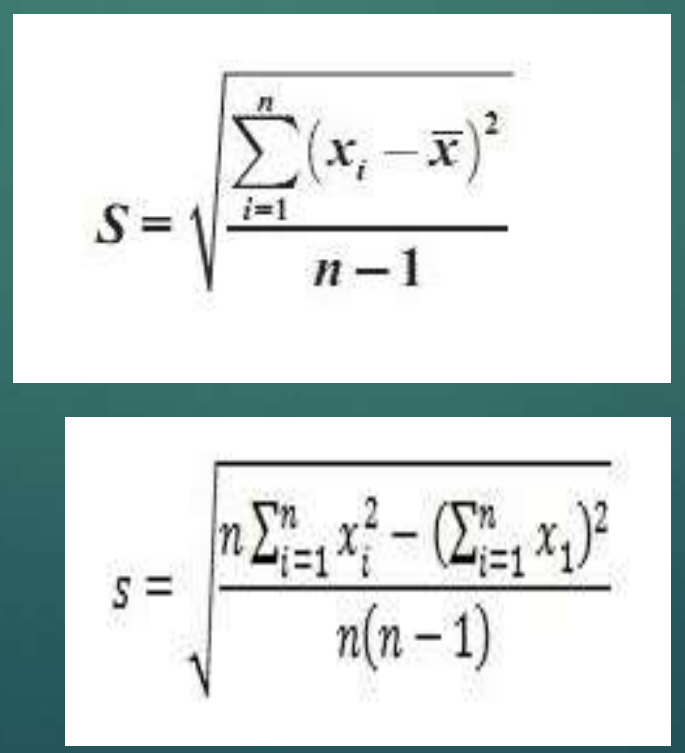




\section{JANGKAUAN KUARTIL}

Kuartil merupakan ukuran yang membagi data menjadi empat bagian yang sama. Seperti yang telah di jelaskan di atas bahwa kuartil terdiri dari kuartil bawah $\left(Q_{1}\right)$, kuartil tengah $\left(Q_{2} /\right.$ median) dan kuartil atas $\left(Q_{3}\right)$.Simpangan kuartil ialah setengah dari selisih kuartil atas dengan kuartil bawah.

Simpangan kuartil $=1 / 2\left(Q_{3}-Q_{1}\right)$

RUMUS :

$\checkmark$ DATA TUNGGAL

$$
J K=\frac{1}{2}(Q 3-Q 1)
$$

$\checkmark$ DATA KELOMPOK

$$
Q_{i}=T b_{i}+\left(\left((i / 4) n-F_{i}\right) / f_{i}\right) c
$$


Persentil ini diambil dari kata persen, per seratus. Maka pengertian dari persentil yakni adalah pembagian data terurut menjadi 100 buah bagian yang sama banyak. Dari 100 buah bagian yang dibagi sama banyak tersebut, dibatasi dengan 99 buah nilai persentil.

RUMUS :

$\checkmark$ DATA TUNGGAL

$\checkmark$ DATA KELOMPOK
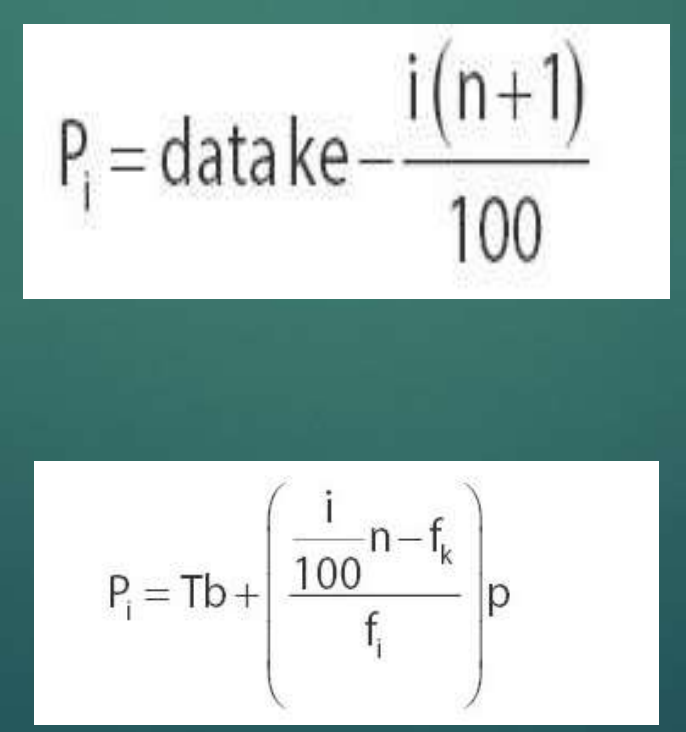


\section{SIMPANGAN RATA RATA MENGGUNAKAN MS.EXCEL}

- DATA TUNGGAL

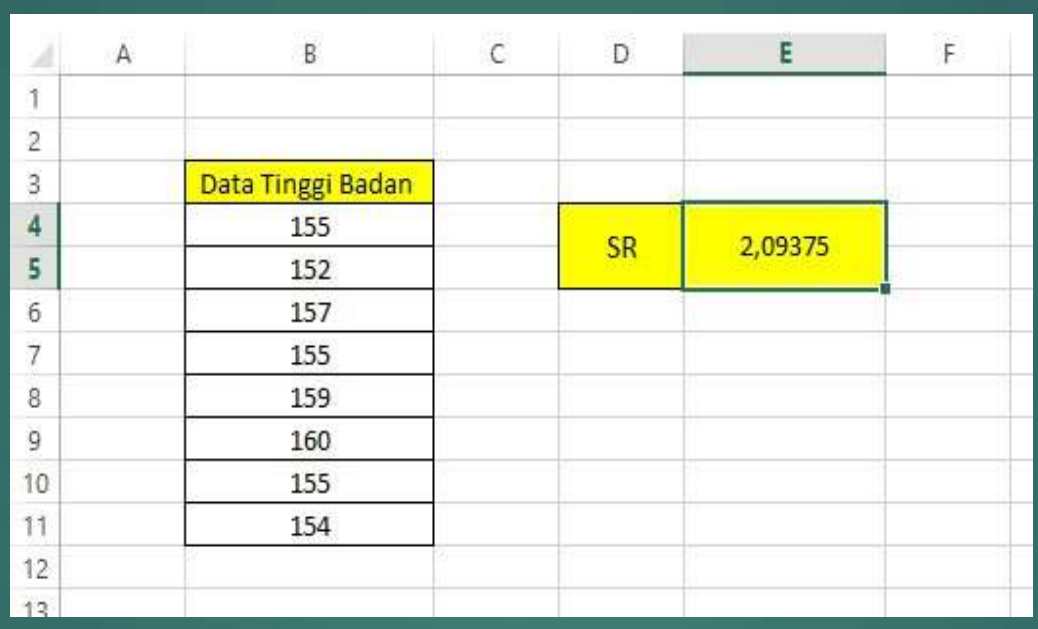

- DATA KELOMPOK

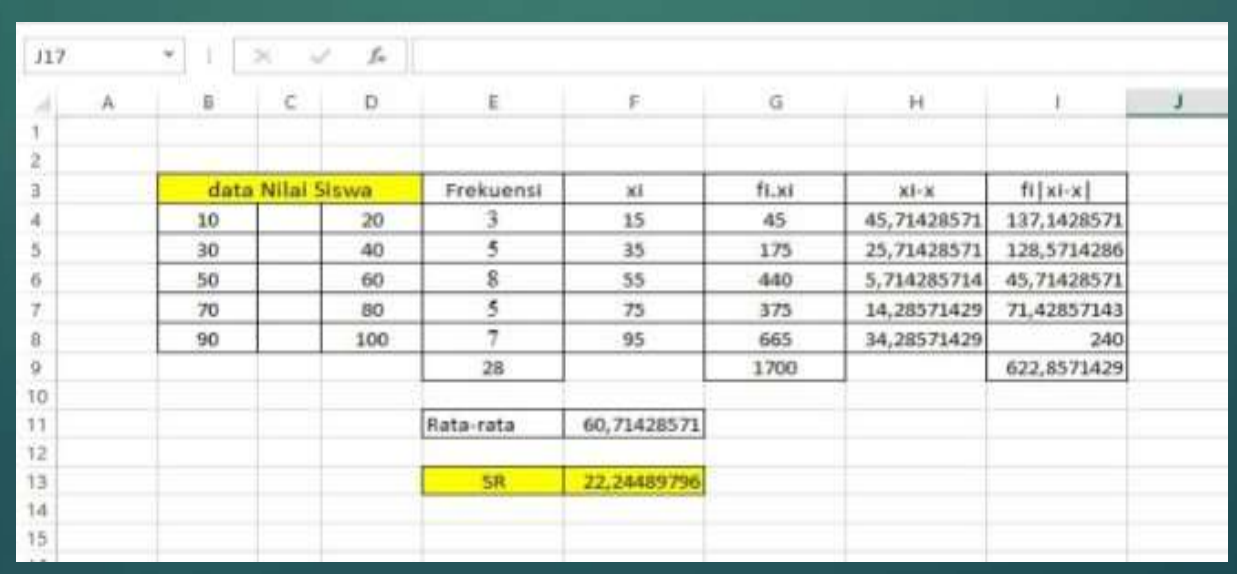


SIMPANGAN RATA RATA MENGGUNAKAN SPSS

DATA TUNGGAL

DESCRIPTIVES VARIABLESTIIIGgISISWa

Descriptives

[Dataset0]

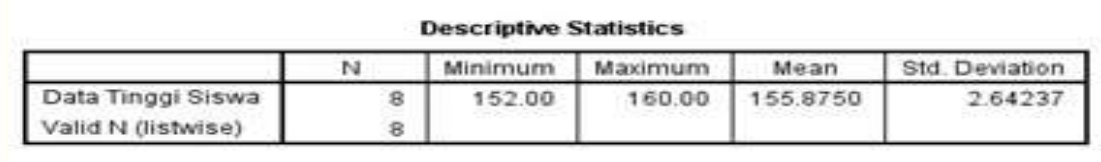

COMPUTE Absolute_Deviation=ABS ( Tingg1Siswa-155.8750) .

EXECUTE.

DESCRIPTIVES VARIABLES=Absolute_DeVIation

/STATISTICS=MEAN STDDEV MIN NAX.

$\rightarrow$ Descriptives

[Dataset0]

Descriptwe Statistics

\begin{tabular}{|l|r|r|r|r|r|}
\hline & N & Minimum & Maximum & Mean & Std. Deviation \\
\hline $\begin{array}{l}\text { Absolute_Deviation } \\
\text { Valid N (listwise) }\end{array}$ & 8 & 88 & 4.13 & 2.0938 & 1.40431 \\
\hline
\end{tabular}

DATA KELOMPOK

\begin{tabular}{|c|c|c|c|c|c|c|c|c|}
\hline \multicolumn{9}{|c|}{ E } \\
\hline \multicolumn{9}{|c|}{$16: S R$} \\
\hline & nilisisiswa & fieturensi & 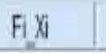 & Xiviliariata2 & xi xxata2 & fixi xxta2 2 & $S R$ & vat \\
\hline 1 & 1500 & 300 & 4500 & 60.71 & 4571 & 137.14 & 2225 & \\
\hline 2 & 3500 & 500 & 17500 & 60.71 & 2571 & 12857 & 2225 & \\
\hline 3 & 55.00 & 8.00 & 440.00 & 60.71 & 5.71 & 45.71 & 2225 & \\
\hline 4 & 75.00 & 5.00 & 375.00 & 60.71 & 14.29 & 71.43 & 22.25 & \\
\hline 5 & 95.00 & 7.00 & 665.00 & 60.71 & 34.29 & 200.00 & 22.25 & \\
\hline 6 & & & & & & & & \\
\hline 7 & & & & & & & & \\
\hline
\end{tabular}




\section{STANDAR DEVIASI MENGGUNAKAN MS.EXCEL}

- DATA TUNGGAL

- DATA KELOMPOK
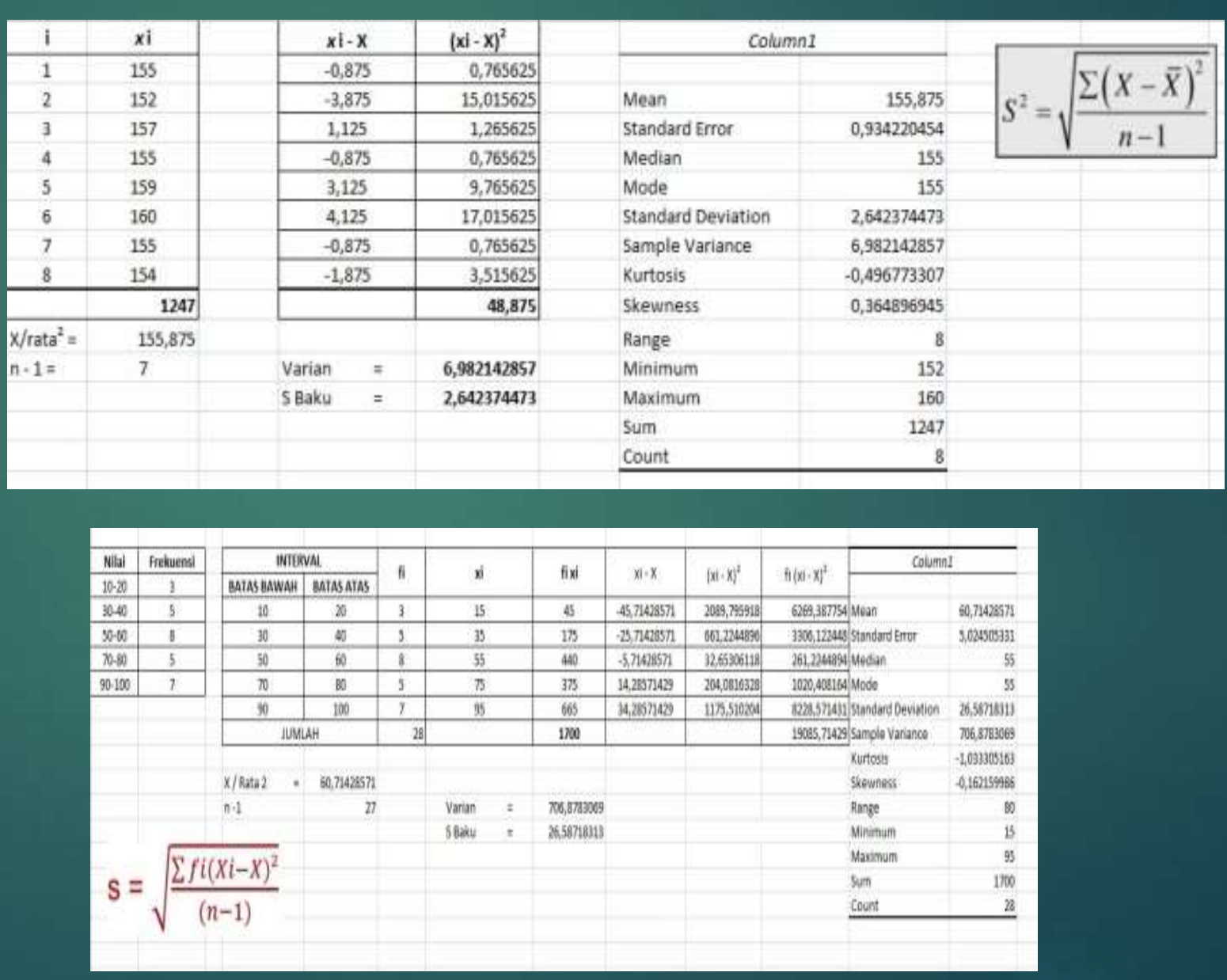


\section{STANDAR DEVIASI MENGGUNAKAN SPSS}

\section{DATA TUNGGAL}

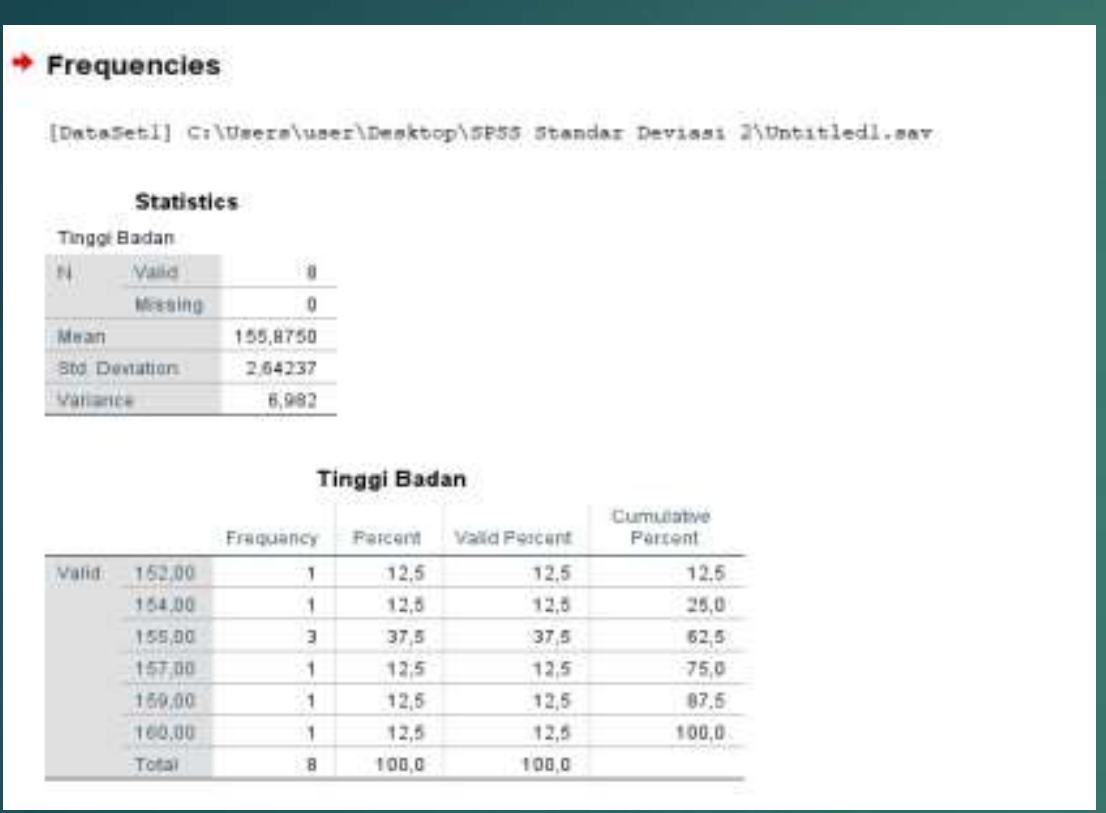

Descriptives

Deseriptive Statistiles

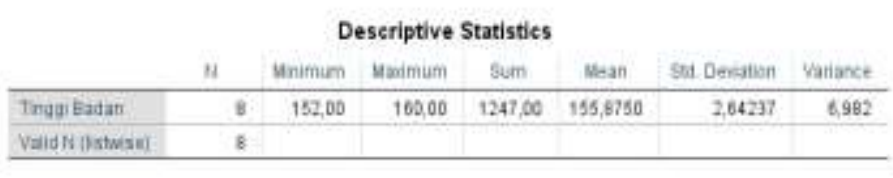

FaEQUEvictes vaRtaALEs-Tingy 1

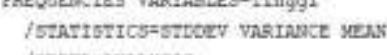

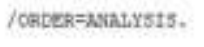

\section{DATA KELOMPOK}

\begin{tabular}{|r|r|}
\hline $\begin{array}{c}\text { Nilaimaha } \\
\text { siswa }\end{array}$ & frekuensi \\
\hline 15,00 & 3,00 \\
\hline 35,00 & 5,00 \\
\hline 55,00 & 8,00 \\
\hline 75,00 & 5,00 \\
\hline 95,00 & 7,00 \\
\hline
\end{tabular}

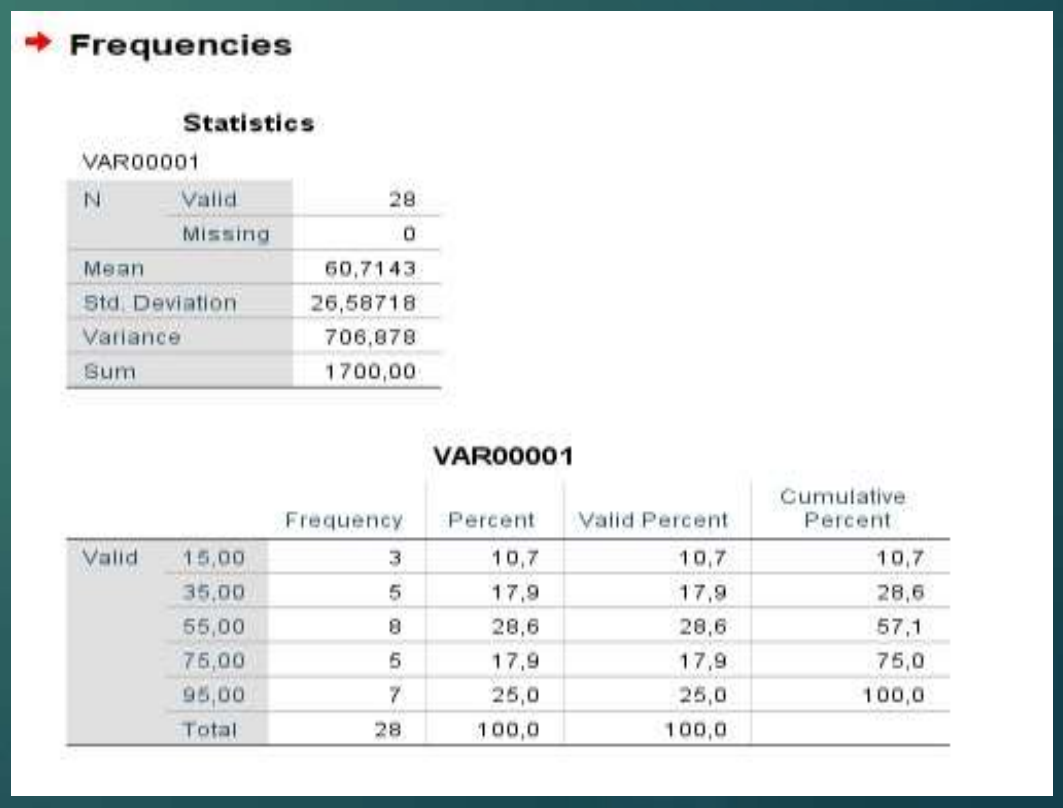




\section{JANGKAUAN KUARTIL MENGGUNAKAN MS.EXCEL}

- DATA TUNGGAL

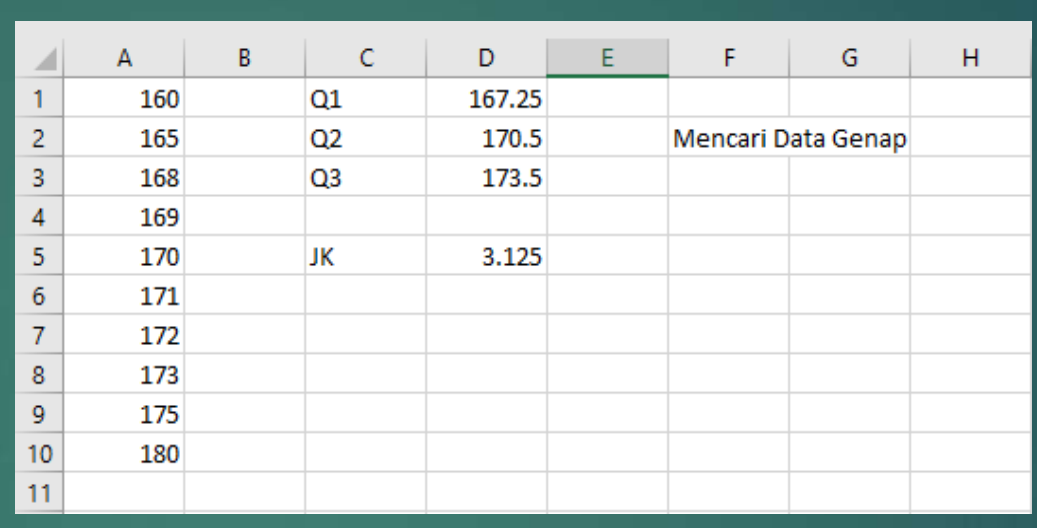

$\checkmark$ DATA KELOMPOK

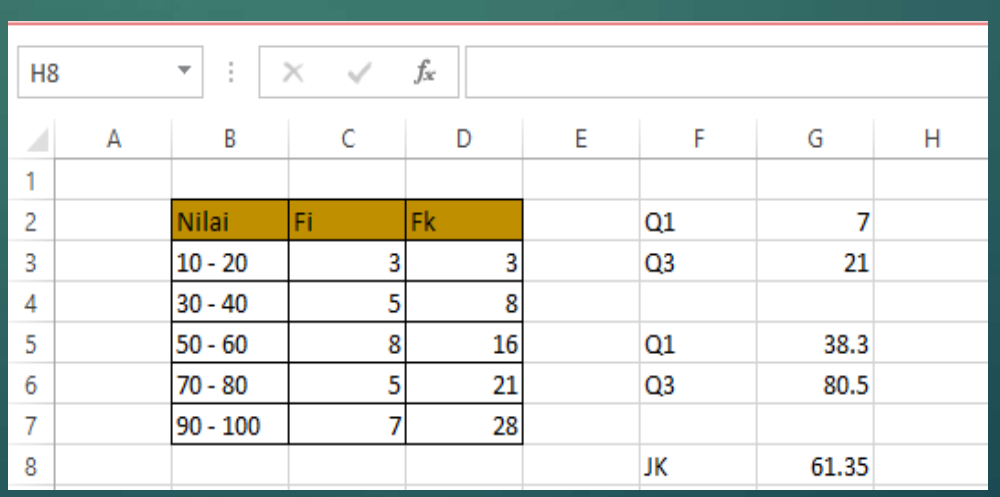




\section{JANGKAUAN KUARTIL MENGGUNAKAN SPSS}

\section{DATA TUNGGAL}

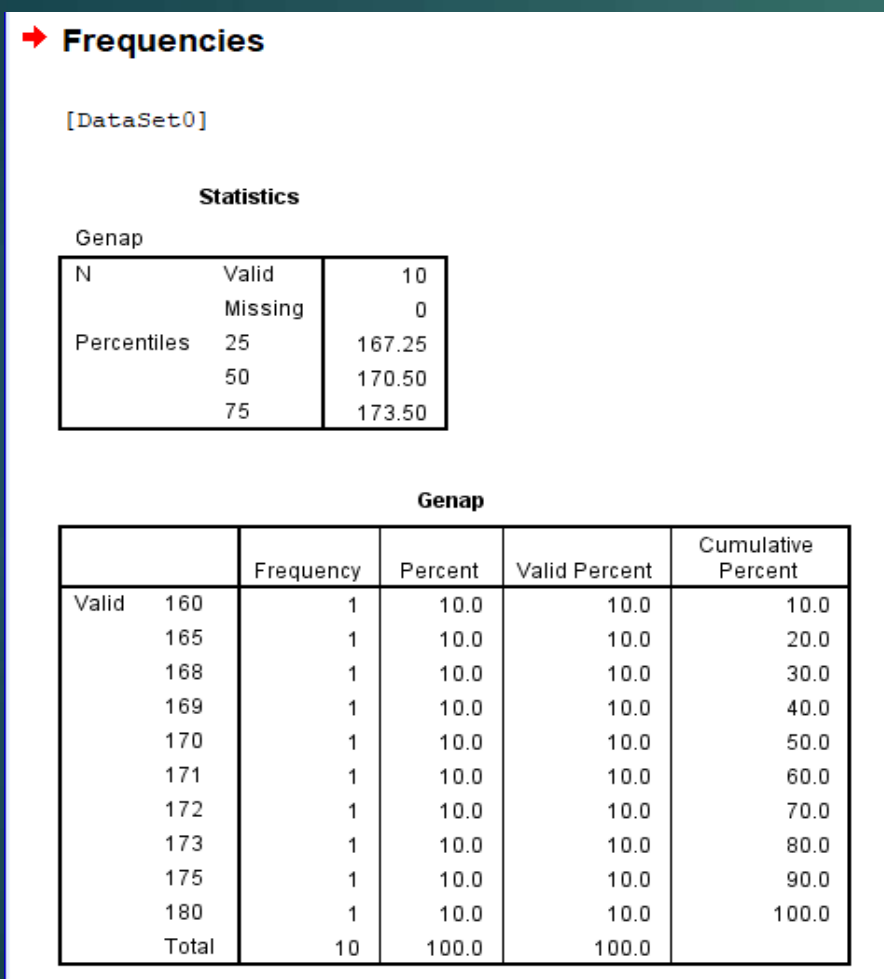

DATA KELOMPOK
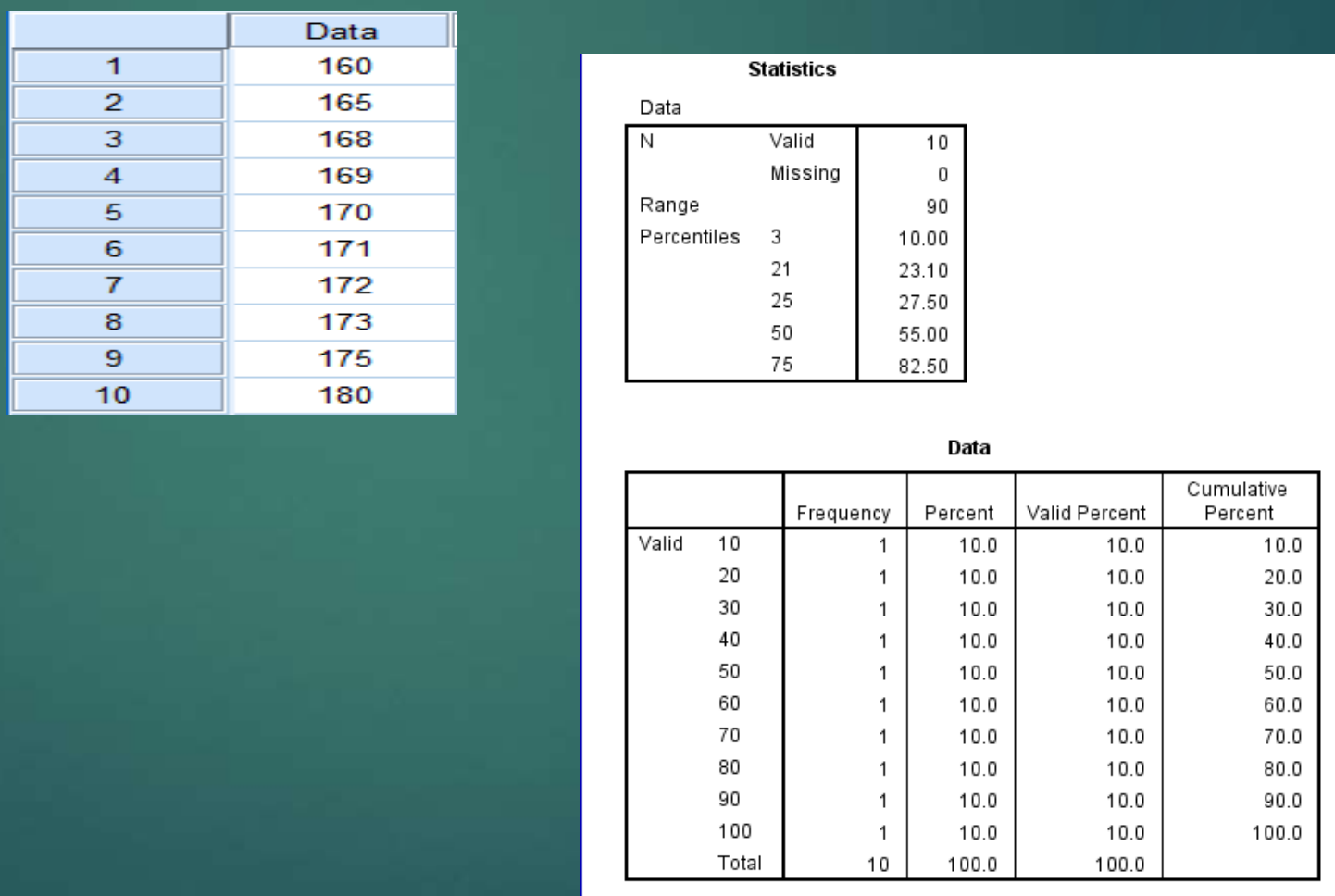


\section{JANGKAUAN PERSENTIL MENGGUNAKAN EXCEL}

- DATA TUNGGAL

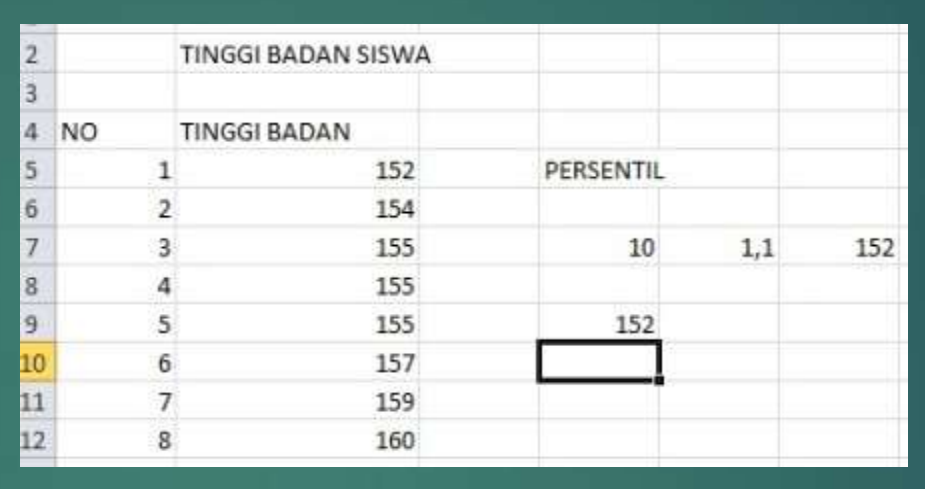

- DATA KELOMPOK

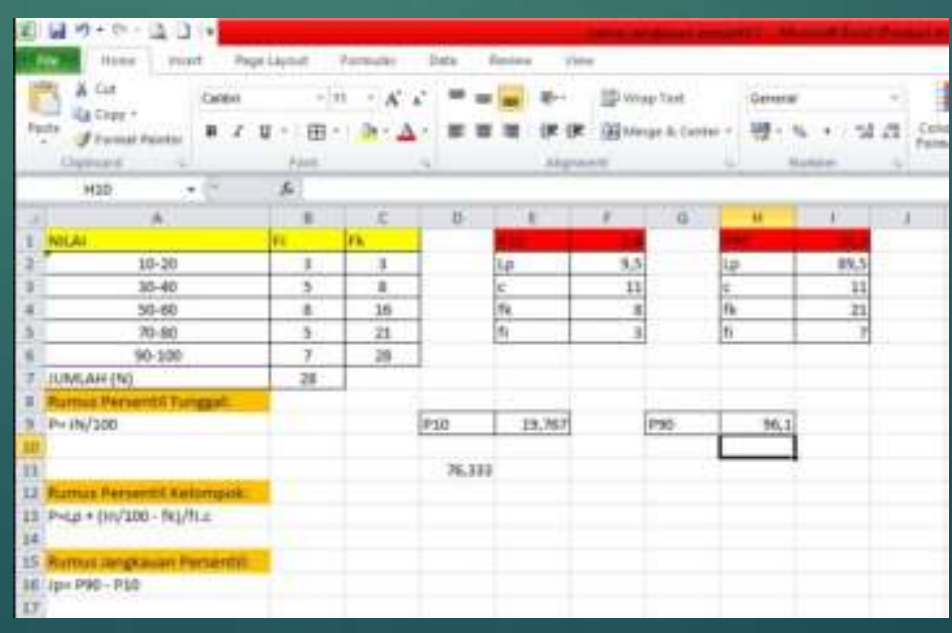




\section{JANGKAUAN PERSENTIL MENGGUNAKAN SPSS}

DATA TUNGGAL

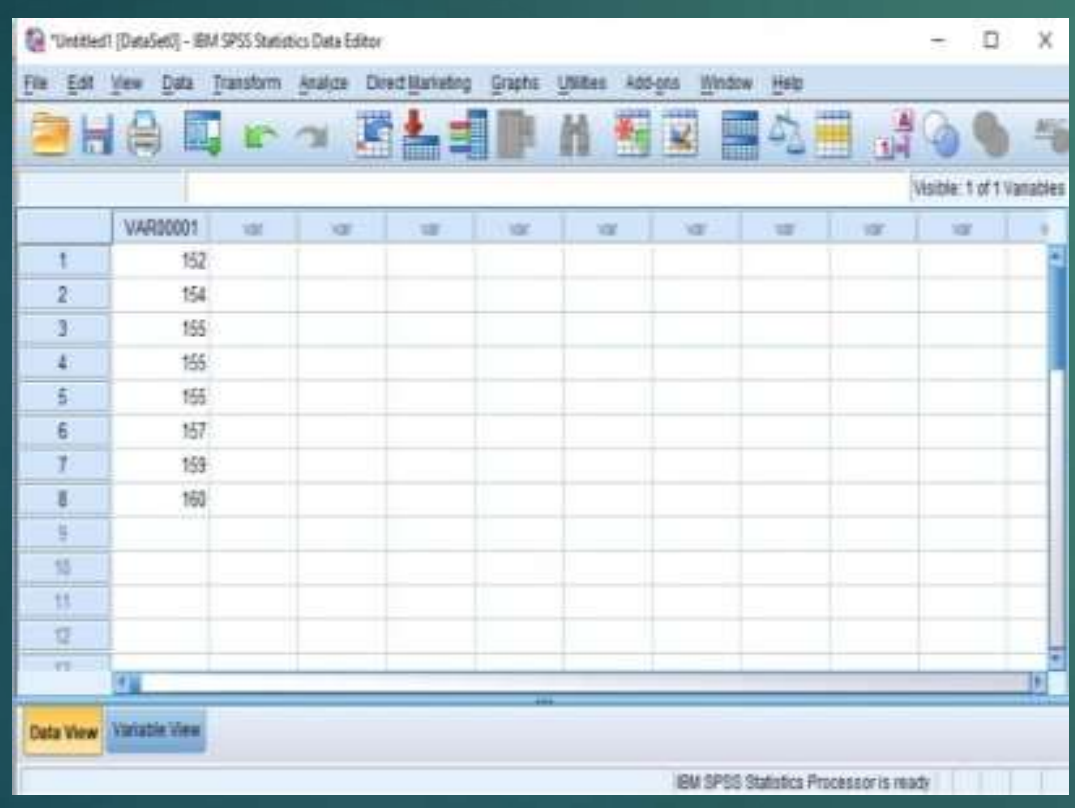

\begin{tabular}{|rr|r|r|r|r|}
\hline & & $\begin{array}{c}\text { Freque } \\
\text { ncy }\end{array}$ & $\begin{array}{c}\text { Perce } \\
\text { nt }\end{array}$ & $\begin{array}{c}\text { Valid } \\
\text { Percent }\end{array}$ & $\begin{array}{c}\text { Cumulati } \\
\text { ve } \\
\text { Percent }\end{array}$ \\
\hline & 152 & 1 & 12,5 & 12,5 & 12,5 \\
& 154 & 1 & 12,5 & 12,5 & 25,0 \\
& 155 & 3 & 37,5 & 37,5 & 62,5 \\
Val & 157 & 1 & 12,5 & 12,5 & 75,0 \\
id & 159 & 1 & 12,5 & 12,5 & 87,5 \\
& 160 & 1 & 12,5 & 12,5 & 100,0 \\
& Tot & 8 & 100,0 & 100,0 & \\
al & & & & \\
\hline
\end{tabular}

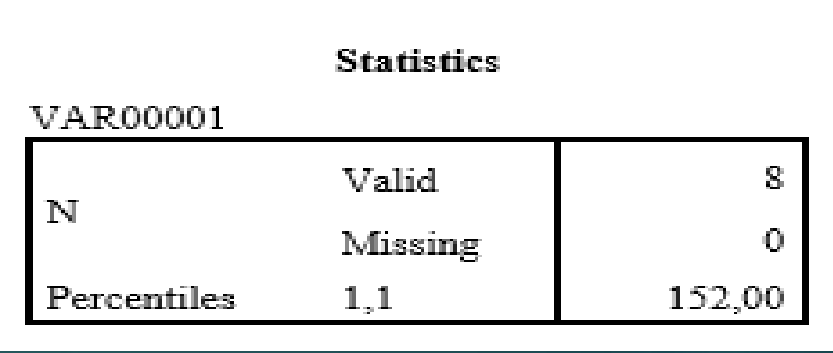




\section{DATA KELOMPOK}
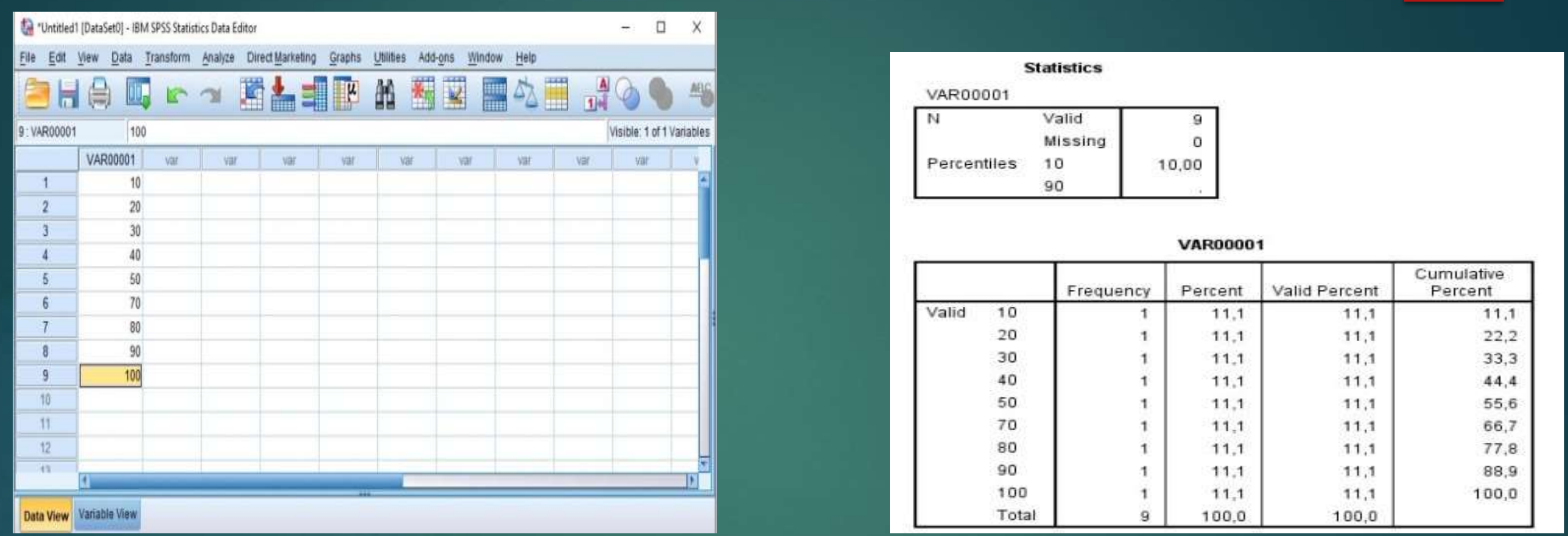